\title{
SECONDARY PREDICATES, VP-INTERNAL SUBJECTS, AND MUTUAL C-COMMAND
}

\author{
Hiroshi Hasegawa \\ Tokyo Institute of Technology
}

\begin{abstract}
This paper investigates the syntactic nature and behavior of three types of secondary predicates. We identify their syntactic positions based on some syntactic evidence. We explain certain data in terms of the crossing constraint, or Pesetsky's Path Containment Condition. We assume VPinternal subjects, and Reinhart's definition of c-command, and show that various facts concerning the behavior of secondary predicates can be elegantly explained as a consequence of the interaction of general constraints such as the mutual c-command restriction and the crossing constraint*
\end{abstract}

1. IntRoduction. Secondary predicates can be classified into three types, namely, resultatives, object-oriented depictives, and subjectoriented depictives, as illustrated below.

(1) a. John painted the car red. (resultative)

b. Bill ate carrots raw. (object-oriented depictive)

c. John left the room angry. (subject-oriented depictive)

The purpose of this paper is to clarify the syntactic properties of each type, and to explain their behavior as a consequence of the interaction of general assumptions and constraints.

2. Resultatives And object-ORIENTEd Depictives. Following Rothstein 1983, we will assume that resultatives are generated under the $\mathrm{V}^{\prime}$ node as a sister of the verb. If we regard resultatives as elements selected by the semantic nature of the verb, we will be able to explain the impos-

* This paper is a revised and extended version of a part of a paper read at a symposium entitled 'Predication', which was held during the 62nd meeting of the English Literature Society of Japan. I am deeply indebted to Heizo Nakajima for letting me participate in the symposium, and for giving me valuable comments and suggestions. I am very grateful to Noriko Imanishi for assisting at various stages of the preparation, and to two anonymous reviewers for comments. I would also like to thank Mr. Hugh Gosden for acting as an informant and correcting stylistic errors. Remaining errors and inadequacies are my own.

English Linguistics 8 (1991) 1-15 - 1 -

(C) 1991 by the English Linguistic Society of Japan 
sibility of 'stacked' resultatives in $2 .{ }^{1}$

(2) *John washed the clothes clean white.

(cf. John washed the clothes clean/white.)

As for object-oriented depictives, we will assume that they are adjoined to $\mathrm{V}^{\prime}$, along the lines of McNulty $1988 .^{2}$ Arguments against this assumption can be found in Imai ed. 1986, where it is argued that objectoriented depictives, as well as resultatives, are generated under the $\mathrm{V}^{\prime}$ node as a sister of the verb. ${ }^{3}$ According to Imai, the ungrammaticality of sentence 3 indicates that object-oriented depictives are generated as a sister of the verb.

(3) *John ate the meat raw, and Bill did so cooked.

The ungrammaticality of sentence 3 , however, does not necessarily show that object-oriented depictives are generated as a sister of the verb, because it can be explained by some other factor, namely, the nonexistence of an NP that functions as the subject of the secondary predicate. Since the VP in the second conjunct has been substituted by do so, there is no NP that functions as the subject of the secondary predicate cooked in sentence $3{ }^{4}$ Hence the ungrammaticality of sentence 3 does not constitute evidence against our claim that object-oriented depictives are adjoined to $V^{\prime}$. Note that sentence 4 is grammatical, because there exists an NP (Bill) that functions as the subject of the secondary predicate

${ }^{1}$ Rothstein 1983 contrasts sentence 2 with sentence (i), where object-oriented depictives, which are not selected by the verb, are 'stacked' freely.

(i) They eat meat raw tender.

But we will see later that this sort of stacking results in unacceptable sentences in most of the cases, as pointed out in McNulty 1988.

2 The assumption that depictive secondary predicates are adjoined to $V^{\prime}$ is in a sense a 'minimal assumption', for they can be regarded as a kind of base-generated adjuncts, and it is generally assumed in the literature that base-generated adjuncts (such as manner adverbs or relative clauses) are in a position adjoined to single-bar level categories, as indicated below.

(i)

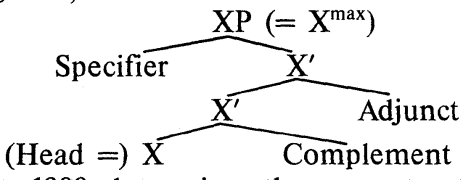

${ }^{3}$ Roberts 1988 also assigns the same structural position to object-oriented depictives.

${ }^{4}$ Note that the NP the meat in the first conjunct cannot function as the subject of the secondary predicate cooked, because they are not in the mutual c-command relation, which we will discuss later. 
sober. ${ }^{5}$

(4) John discussed the topic drunk, and Bill did so sober.

Let us now consider sentences like $5 .^{6}$

(5) a. (?)We hammered the metal flat hot

(cf. *We hammered the metal hot flat)

b. (?)You can knead clay soft wet.

As is clear from the sentences in 5, resultatives must precede objectoriented depictives when they co-occur. Assuming that resultatives are generated as a sister of the verb, while object-oriented depictives are adjoined to $\mathrm{V}^{\prime}$, we get a VP structure like $5^{\prime}$ for sentence $5 \mathrm{a}$, and the fixed order of the two types of predicates directly follows.

$\left(5^{\prime}\right)$

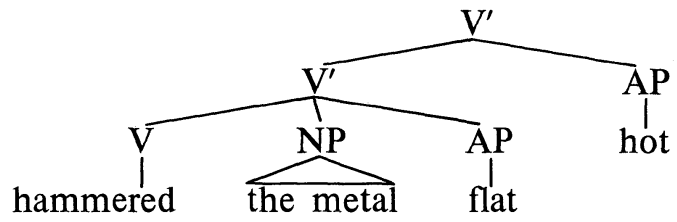

But if one assumed, as in Imai ed. 1986, that both resultatives and object-oriented depictives were generated under the $\mathrm{V}^{\prime}$ node as a sister of the verb, the fixed order of the two types would be hard to explain. Imai tries to account for this by assuming a VP structure like $5^{\prime \prime}$ for sentence $5 \mathrm{~b}$.

$\left(5^{\prime \prime}\right)$

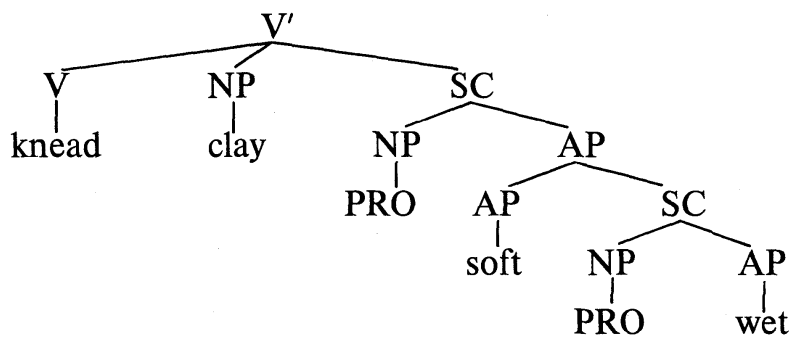

This, however, does not seem to be the correct phrase structure for sentences like 5. Consider the following. ${ }^{7}$

(6) ?You can [knead clay soft] and [pound it flat] wet.

5 The same point is made in Nakajima 1990.

${ }^{6}$ McNulty 1988 claims that sentences of this sort are unacceptable to some speakers, as we will discuss later.

7 This sentence is unacceptable to speakers who reject sentences like 5. But to speakers who accept sentences like 5 , sentence 6 seems marginally acceptable, or at least preferable to sentence 7 . 
In sentence 6, knead clay soft appears as a conjunct of a coordinate structure. This indicates that knead clay soft in sentence $5 \mathrm{~b}$ forms a constituent. According to our analysis, knead clay soft in $5 \mathrm{~b}$ forms a constituent, and the (marginal) acceptability of sentence 6 is correctly predicted. If one assumed a structure like $5^{\prime \prime}$ for sentences like 5 , however, knead clay soft would not form a constituent, and one would not be able to account for the acceptability of sentence 6. Note, on the other hand, that sentence 7 is unacceptable.

( 7 ) ?*John hammered the metal flat hot and thin warm.

If one assumed a structure like $5^{\prime \prime}$, a resultative and an object-oriented depictive would form a constituent, and one would incorrectly predict that sentence 7 would be acceptable. According to our analysis, a resultative and an object-oriented depictive do not form a constituent, and the unacceptability of sentence 7 directly follows.

So far, we have shown that we have no strong evidence for generating object-oriented depictives under the $\mathrm{V}^{\prime}$ node as a sister of the verb, and that we can account for the facts more naturally if it is assumed that object-oriented depictives are adjoined to $\mathrm{V}^{\prime}$.

There may be a possibility that resultatives as well as object-oriented depictives are adjoined to $V^{\prime}$. This assumption, however, gives rise to the same sort of problem as discussed above: we must assume that they are at different structural positions in order to account for the fact that resultatives must precede object-oriented depictives when they co-occur (as in sentences $5 \mathrm{a}$ and $5 \mathrm{~b}$ ).

3. SUBJECT-ORIENTED DEPICTIVES AND THE CROSSING CONSTRAINT. Williams 1980, Rothstein 1983, and Nakajima 1989 assume that subjectoriented depictives are attached to the matrix S node. ${ }^{8}$ Andrews 1982 argues against this and show that they form a constituent with the $\mathrm{VP}$, based on the following data. ${ }^{9}$

( 8 ) a. John said he would eat the meat nude, and $\mathrm{lvp}_{\mathrm{vp}}$ eat the meat nude] he did.

${ }^{8}$ In section 5, we will present an argument against Nakajima's (1989) claim that subject-oriented depictives are generated as a daughter of the matrix $\mathrm{S}$.

9 Roberts 1988 also gives the same sort of data. An example like 8d was pointed out to me by Shigeo Tonoike (personal communication). Ushie 1991 claims that the acceptability of sentences like 8 does not necessarily preclude the possibility that subject-oriented depictives can be EITHER inside the VP oR attached to the matrix S. This possibility will not be pursued here. 
b. [vp eat the meat nude] though John did, nobody thought he was crazy.

c. What John did was [vp eat the meat nude].

d. John [vp wrecked the car drunk] and [vp called the police sober].

We will assume that subject-oriented depictives as well as objectoriented depictives are adjoined to $\mathrm{V}^{\prime}$. McNulty 1988 tries to explain certain facts by assuming that object-oriented depictives are adjoined to $\mathrm{V}^{\prime}$ whereas subject-oriented depictives are adjoined to VP. We will argue that we do not need to assume different structural positions for these two types of secondary predicates, because their different behavior can be attributed to some other independent factors.

Consider the following sentences, in which object-oriented depictives and subject-oriented depictives co-occur.

(9) a. John eats the meat raw drunk.

b. *John eats the meat drunk raw.

(10) a. John ate the salad undressed naked.

b. *John ate the salad naked undressed.

As is clear from sentences 9 and 10, object-oriented depictives always precede subject-oriented depictives. McNulty 1988 tries to account for these data by assuming different structural positions for these two types of secondary predicates. These facts, however, can be explained by a general constraint, namely, the crossing constraint (or the Nested Dependency Constraint, in Fodor's (1978) terms). Sentence 9a is acceptable because the subject-predicate dependencies are in a 'nested' relation, as indicated below. But in 9b, they are in a 'crossing' relation, and the sentence is unacceptable. ${ }^{10}$

$\left(9^{\prime}\right)$
a. John ate the meat raw drunk
b. *John ate the meat drunk raw

Pesetsky's (1982, 1983) Path Containment Condition (PCC) restates the crossing constraint as a condition on phrase markers rather than a linear constraint.

10 The same point is made in Rochemont and Culicover 1990, where it is claimed that their interpretive nesting requirement extends also to predication relations. 
(11) Path Containment Condition (PCC)

When two paths overlap, one must contain the other. ${ }^{11}$

Pesetsky regards his PCC as a condition on A-bar dependencies. But since PCC is originally an expansion of the crossing constraint, it seems plausible to extend PCC to other dependencies that are subject to the crossing constraint. Since subject-predicate dependencies are subject to the crossing constraint in English (as also pointed out in Rochemont and Culicover 1990), it seems plausible to apply PCC also to subject-predicate dependencies. $^{12}$

If we assume that a path is created between a subject and a predicate, we will have a path between John and drunk as well as between the meat and raw, as shown in $9^{\prime \prime}{ }^{13}$

$\left(9^{\prime \prime}\right)$

a.

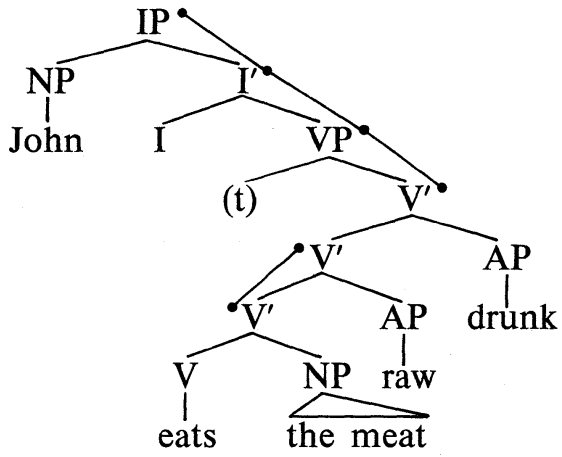

${ }^{11}$ Instead of defining paths in terms of 'maximal projection', we will adopt the definition of paths in Pesetsky 1983, where paths are defined in terms of 'first branching node'. This possibility is also suggested in Pesetsky 1982.

${ }_{12}$ Pesetsky (1982) himself assumes paths for dependencies other than A-bar dependencies in some cases: for instance, he assumes paths between conjuncts in a coordinate structure.

13 The trace directly dominated by the VP node indicates the deep structure position of VP-internal subjects, but whether or not we assume VP-internal subjects is not crucial here. 
b.

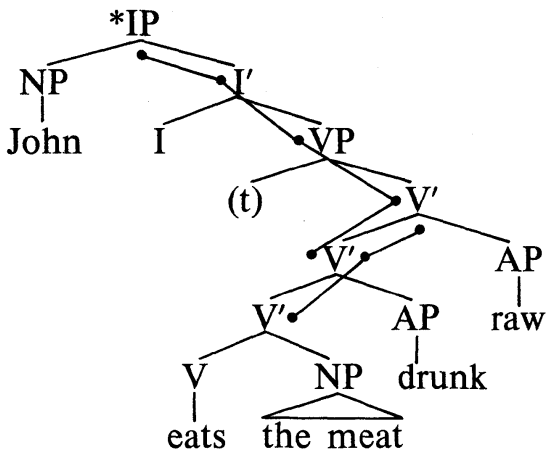

Since the two paths do not overlap in 9" a, sentence 9a does not violate PCC and therefore is well-formed. In $9^{\prime \prime} \mathrm{b}$, the two paths overlap and neither path contains the other; hence the ungrammaticality.

Thus, we have shown that we can account for the (un)grammaticality of sentences like 9 and 10 without assuming the different structural positions for object-oriented depictives and subject-oriented depictives as in McNulty $1988 .{ }^{14}$

4. VP-INTERNAL SUBJECT HYPOTHESIS AND MUTUAL C-COMMAND. Roberts 1988 tries to account for the behavior of secondary predicates by assuming VP-internal subjects (cf. Fukui 1986) and the mutual c-command restriction. According to Roberts, the deep structure of sentence 1c would resemble $12 .{ }^{15}$

(12)

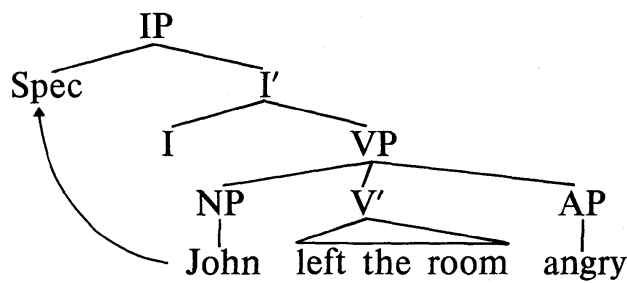

14 Note that we cannot explain the fixed order of the resultatives and objectoriented depictives in sentences like 5 in terms of the crossing constraint, because they are both 'object-oriented'. Therefore we must attribute their fixed order to their different structural positions.

${ }_{15}$ Note that the phrase structure in 12 is not exactly equal to the phrase structure we are assuming, because, under our assumptions, subject-oriented depictives are adjoined to $\mathrm{V}^{\prime}$. 
The subject NP John is generated inside the VP at D-structure, and is raised to the Spec of IP position at S-structure. Roberts argues that the mutual c-command relation holds between the subject NP (John) and the secondary predicate (angry) at D-structure. ${ }^{16}$

Roberts 1988 claims that the mutual c-command restriction must apply at D-structure because the subject moves out of the c-command domain of the secondary predicate at S-structure. But if the moved subject leaves a trace behind and forms a CHAIN with it, the mutual c-command relation holds between the subject and the secondary predicate also at $\mathrm{S}$ structure by means of the CHAIN. Therefore we will assume here that the mutual c-command restriction applies at S-structure.

We will show that by assuming VP-internal subjects and the mutual ccommand restriction based on Reinhart's $(1976,1983)$ definition of ccommand, we can give an elegant account for the behavior of secondary predicates.

Following Reinhart 1976, 1983, we will define c-command as follows.

(13) Node A c-commands Node B iff the branching node $\alpha_{1}$ most immediately dominating $\mathrm{A}$ either dominates $\mathrm{B}$ or is immediately dominated by a node $\alpha_{2}$ which dominates $\mathrm{B}$, and $\alpha_{2}$ is of the same category type as $\alpha_{1}$.

According to this definition, Node A c-commands Node B not only in a configuration like $14 \mathrm{a}$, but also in $14 \mathrm{~b}$, provided that $\alpha_{2}$ is of the same category type as $\alpha_{1}$.

a.

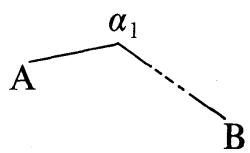

b.

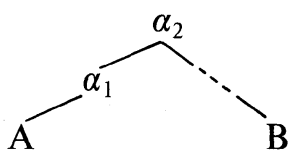

By assuming the mutual c-command restriction based on this definition of c-command, we can account for the facts discussed below.

According to McNulty 1988, subject-oriented depictives cannot be stacked, as shown in 15 .

(15) *John left drunk angry.

McNulty 1988 rules out sentences like 15 by postulating the following

${ }^{16}$ Roberts 1988 seems to adopt the 'simplified' definition of c-command, not Reinhart's final definition given in 13. If one adopts the 'simplified' definition, one will have to assume (as does Roberts) that an object-oriented depictive is generated under the $V^{\prime}$ node as a sister of the verb, or else it will not mutually c-command the object. This, however, is not a plausible assumption, as we have already argued in section 2 . 
condition.

(16) Locality Condition on XP Theta Role Assignment (LCXP) $\mathrm{A}$ assigns a theta role to $\mathrm{B}$ iff $\mathrm{A}$ mutually $\mathrm{m}$-commands $\mathrm{B}$ and there is no $\mathrm{Z}$ such that $\mathrm{Z}$ mutually m-commands $\mathrm{A}$, where $\mathrm{A}, \mathrm{Z}=$ theta assigning XPs.

According to her account of sentence 15, theta role assignment of drunk $(=\mathrm{A})$ to John $(=\mathrm{B})$ is blocked by the existence of angry $(=\mathrm{Z})$ that mutually $\mathrm{m}$-commands drunk $(=\mathrm{A})$, and the sentence is ruled out.

But as McNulty herself points out, her LCXP also rules out sentences like 5 , where a resultative and an object-oriented depictive co-occur.

(5) a. (?)We hammered the metal flat hot.

b. (?)You can knead clay soft wet.

McNulty claims that sentences like 5 are in fact unacceptable for some speakers, and has a hard time explaining why sentences like 5 are exempt from her LCXP and are acceptable for other speakers.

In our analysis, on the other hand, the ungrammaticality of sentences like 15 directly follows, and no such ad hoc condition as LCXP is needed to rule them out. The acceptability of sentences like 5 also directly follows under our analysis.

According to our assumptions, the putative phrase structure of sentence 15 would be like $15^{\prime}$.

$\left(15^{\prime}\right)$

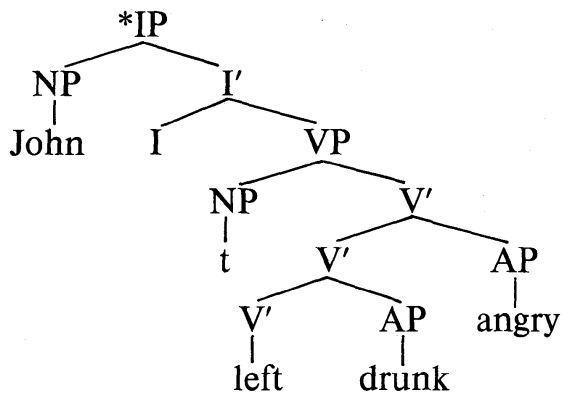

Under Reinhart's definition of c-command, the secondary predicate angry c-commands the trace of the subject John, and the mutual ccommand relation holds between the subject (trace) and angry. But since drunk does not c-command the subject trace, the mutual ccommand restriction is violated, and sentence 15 is ruled out.

Our analysis of the VP structure of sentence $5 \mathrm{a}$ is reproduced below. 
$\left(5^{\prime}\right)$

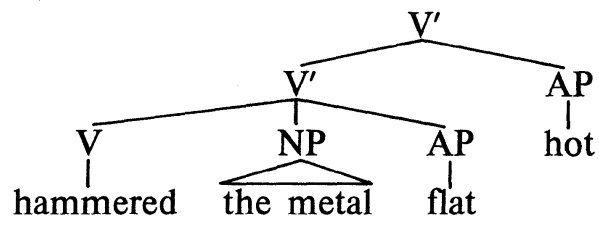

Both the resultative (flat) and the object-oriented depictive (hot) mutually c-command the NP the metal, and the acceptability of sentences like 5 is correctly predicted.

Now why are sentences like 5 unacceptable for some speakers? We assume that for those speakers, an NP can function as the subject of at most one secondary predicate. ${ }^{17}$ Sentence $5 \mathrm{a}$ is unacceptable for those speakers because the NP the metal functions as the subject of two secondary predicates, namely, flat and hot. Compare $5 \mathrm{a}$ with sentence 9a, reproduced here.

(9) a. John ate the meat raw drunk.

Even for those speakers who reject sentences like 5a, sentence 9a is acceptable, because neither of the two NPs (John and the meat) functions as the subject of more than one secondary predicate in $9 \mathrm{a}$.

Now let us consider the following data, which are from McNulty 1988.

a. *Bill ate the meat raw marinated frozen.

b. *Mary bought the bureau painted broken.

c. *Sue mailed the manuscript unfinished torn.

d. *Fred drank the beer cold flat.

According to McNulty, object-oriented depictives cannot be stacked, as shown in $17 .{ }^{18}$ The VP structure of sentence $17 \mathrm{~d}$ would be something like $17^{\prime}$ under our assumptions.

17 This statement that an NP can function as the subject of at most one secondary predicate for some speakers might appear equally as ad hoc as McNulty's LCXP. But since this statement describes a dialectal variation, it is in a sense 'ad hoc by nature'. It should be contrasted with McNulty's LCXP, which is intended to be a general syntactic condition and hence is not supposed to be ad hoc.

18 As already stated in footnote 1, Rothstein 1983 gives the following example as an acceptable sentence, where object-oriented depictives are stacked.

(i) They eat meat raw tender.

But according to McNulty, sentence (i) becomes acceptable only when there is a pause between raw and tender, and they will receive a 'conjoined' interpretation. 
$\left(17^{\prime}\right)$

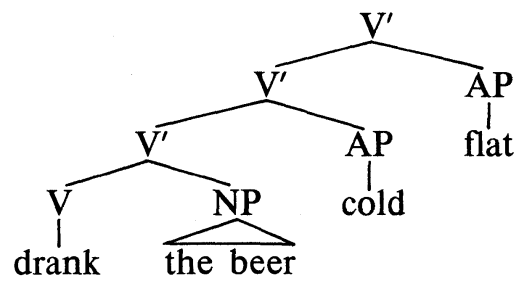

Under Reinhart's definition of c-command, the mutual c-command relation holds between cold and the beer, but not between flat and the beer. The mutual c-command restriction is violated, and the sentence is ruled out.

Thus, we have shown that by assuming VP-internal subjects and the mutual c-command restriction based on Reinhart's definition, we can give an elegant explanation for various facts, without postulating any ad hoc conditions.

5. FURTHER PROBLEMS. In this section we will show the validity of our explanation by offering an elegant account for further data.

Consider the following pair of sentences, which are from Tsuzuki 1990.

(18) a. Mary ate the dinner greedily drunk.

b. ?*Mary ate the dinner drunk greedily.

The putative phrase structures of sentences $18 \mathrm{a}$ and $18 \mathrm{~b}$ are given below.

$\left(18^{\prime}\right)$ a.

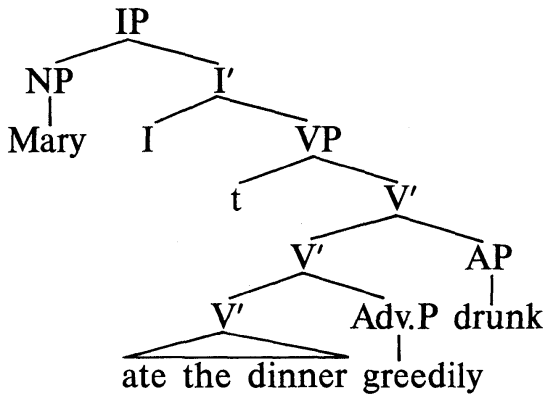

b.

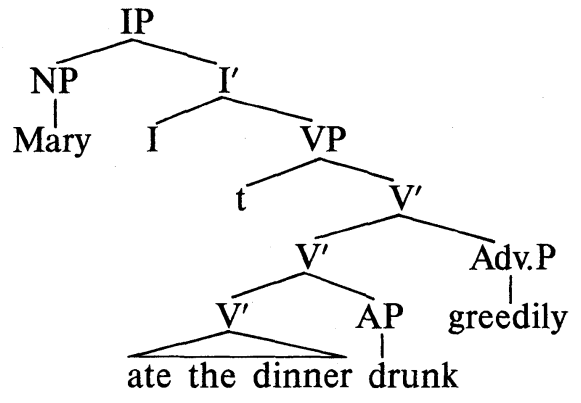


In $18^{\prime} \mathrm{a}$, the mutual c-command relation holds between drunk and the trace of the subject Mary, and sentence 18a is grammatical. In $18^{\prime} \mathrm{b}$, drunk does not mutually c-command the trace of Mary, and the ungrammaticality of sentence $18 \mathrm{~b}$ is correctly predicted. Let us now look at sentences 19a and 19b, also from Tsuzuki 1990.

(19) a. Mary ate the meat raw greedily.

b. *Mary ate the meat greedily raw.

The VP structures of the sentences in 19 are given in $19^{\prime}$.

$\left(19^{\prime}\right)$ a.

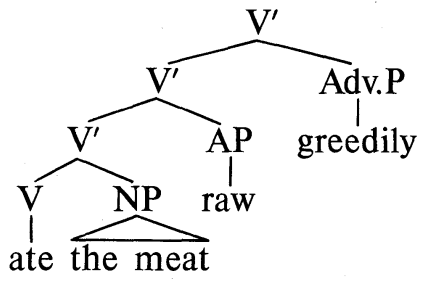

b.

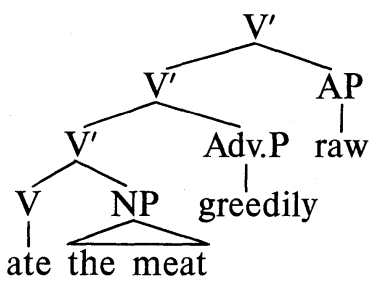

In $19^{\prime} \mathrm{a}$, raw and the meat are in the mutual c-command relation, and sentence 19a is well-formed. In $19^{\prime} \mathrm{b}$, raw does not mutually c-command the meat, and our prediction is born out by the ungrammaticality of sentence $19 \mathrm{~b}$.

The following data are from Nakajima 1989.

(20) a. [NP Many people t] came in angry $\left[_{\mathrm{CP}}\right.$ who were wearing funny hats].

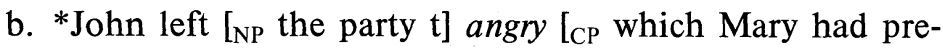
pared since the last weekend].

Nakajima regards the ungrammaticality of sentence $20 \mathrm{~b}$ as evidence that subject-oriented depictives are attached to the matrix S node. Sentence $20 \mathrm{~b}$, however, is ruled out by the crossing constraint discussed in section 3. The subject-predicate dependency between John and angry and the gap-filler dependency between the extraposed $\mathrm{CP}$ and its trace constitute a crossing constraint violation, as indicated in $20^{\prime}$.

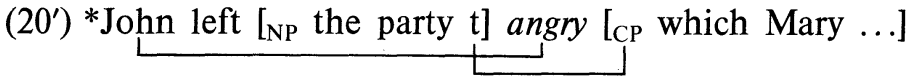

Hence the ungrammaticality of sentence $20 \mathrm{~b}$ does not constitute evi- 
dence that subject-oriented depictives are attached to the matrix $\mathrm{S}$ node as is claimed by Nakajima. It is not clear whether 20a constitutes a crossing constraint violation as long as we regard the constraint as a linear one. If we assume Pesetsky's PCC instead of a linear constraint, however, the facts become clear.

$\left(20^{\prime \prime}\right)$

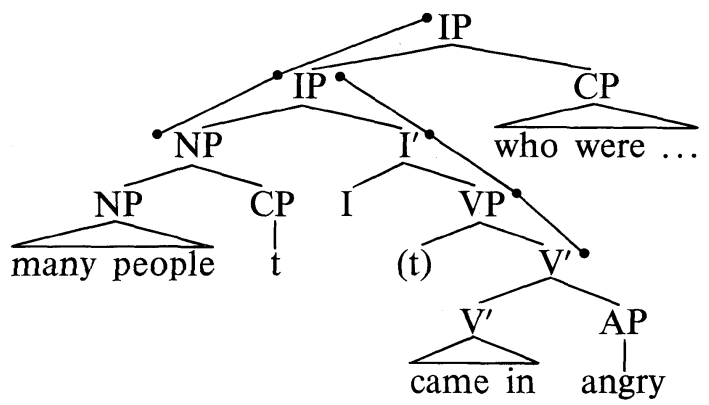

According to Pesetsky's definition, two paths do not 'overlap' when the intersection of the two paths is a single node. Hence the path between the subject NP and the predicate angry does not 'overlap' with the path between the extraposed CP and its trace. Since PCC is not violated, sentence $20 \mathrm{a}$ is grammatical. ${ }^{19}$

Now reconsider sentence $9 \mathrm{~b}$, reproduced here.

(9) b. *John ate the meat drunk raw.

In section 3 , we ruled out sentence $9 \mathrm{~b}$ in terms of the crossing constraint, or Pesetsky's PCC. Sentence $9 b$, however, is ruled out also by the mutual c-command restriction. The phrase structure of $9 \mathrm{~b}$ is reproduced below.

19 These sorts of paths may have to be distinguished from A-bar dependency paths created by wh-movement. Rochemont and Culicover 1990 make a similar point based on the following data.

(i ) Which of the rooms did [a man (t)] walk into $t$ [who you had never seen before]?

In sentence (i), the dependency path between the wh-phrase and the trace and the one between the extraposed relative clause and the subject are in a 'crossing' relation. According to their judgement, however, the sentence is acceptable. Rochemont and Culicover regard the acceptability of sentence (i) as evidence that extraposition constructions do not involve any A-bar movement dependency. 
$\left(9^{\prime \prime}\right)$

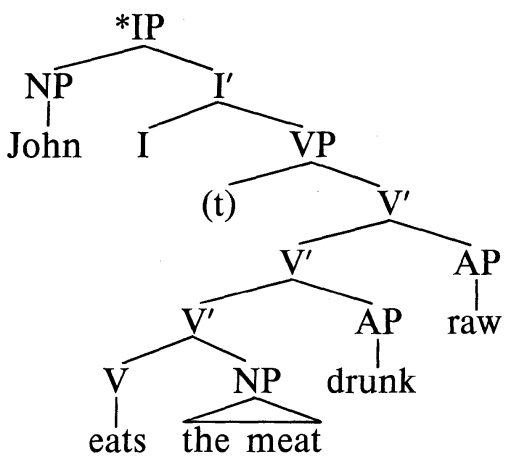

In $9 " \mathrm{~b}$, neither raw mutually c-commands the meat, nor drunk mutually c-commands the trace of the subject John. Hence sentence $9 \mathrm{~b}$ is ruled out also by the mutual c-command restriction.

Since sentence $9 \mathrm{~b}$ is ruled out both by the crossing constraint and by the mutual c-command restriction, it might appear redundant to assume both of the constraints. But that some sentences are ruled out by both does not necessarily mean that the two constraints are redundant. Compare sentence $9 \mathrm{~b}$ with sentence $17 \mathrm{~d}$, in which object-oriented depictives are stacked.

d. *Fred drank the beer cold flat.

$17 \mathrm{~d}$ is a violation of the mutual c-command restriction, as discussed in the previous section. But it does not violate the crossing constraint, because both cold and flat are object-oriented. Now stacking object-oriented depictives can sometimes result in an acceptable sentence, as is claimed by Rothstein (See footnote 1), while there are no acceptable examples of the type in $9 \mathrm{~b}$. We can account for the lower acceptability of sentences like $9 \mathrm{~b}$ if we assume that they violate more constraints than sentences like 17d. Hence it seems plausible to assume both of the constraints, namely, the crossing constraint and the mutual c-command restriction.

6. Conclusion. We have shown that by assuming VP-internal subjects and Reinhart's definition of c-command, we can account for the behavior of three types of secondary predicates as a consequence of the interaction of general constraints such as the crossing constraint and the mutual c-command restriction. Further research is necessary to clarify the exact nature of secondary predicates and the factors that determine their behavior under various circumstances. 


\section{REFERENCES}

ANDREWS, AVERY. 1982. A note on the constituent structure of adverbials and auxiliaries. LI 13.313-7.

FODOR, JANET DEAN. 1978. Parsing strategies and constraints on transformations. LI 9.427-73.

FUKUI, NAOKI. 1986. A theory of category projections and its applications. MIT dissertation.

IMAI, KUNIHIKO. (ed.) 1986. Chomsky sho-jiten. Tokyo: Taishukan.

MCNUlTy, Elaine. 1988. The syntax of adjunct predicates. The University of Connecticut dissertation.

NAKAJIMA, HEIZO. 1989. Shujutsu-kankei no sho-mondai (Problems in subjectpredicate relation). The Rising Generation 135.374-6, 443-5.

—. 1990. Secondary predication. Linguistic Review 7.275-309.

PESETSKY, DAVID. 1982. Paths and categories. MIT dissertation.

- 1983. Problems in GB theory. A paper presented at Tokyo Linguistic Seminar.

REINHART, TANYA. 1976. The syntactic domain of anaphora. MIT dissertation.

- 1983. Anaphora and semantic interpretation. London: Croom Helm.

ROBERTS, IAN. 1988. Predicative APs. LI 19.703-10.

Rochemont, MiCHAEL, and PETER CuliCOVER. 1990. English focus construction and the theory of grammar. Cambridge: Cambridge University Press.

RothSTEIN, SUSAN. 1983. The syntactic forms of predication. MIT dissertation.

TSUZUKI, MASAKO. 1990. Secondary Predication. A paper presented at the $62 \mathrm{nd}$ meeting of the English Literature Society of Japan.

USHIE, KAZUHIRO. 1991. Niji-teki jutsugo no kozo-jo no ichi ni tsuite no oboegaki (A note on the structural position of secondary predicates). Gendai eigogaku no shosō (Aspects of modern English linguistics: A festschrift for Dr. Masatomo Ukaji), ed. by Shuji Chiba et al., 470-9. Tokyo: Kaitakusha.

Williams, EDWIN. 1980. Predication. LI 11.203-38. 